\title{
Introducing Master's Students to Area Studies: An Interdisciplinary Research and Skills Approach
}

\author{
John T. Morris, University of Connecticut
}

Master's programs in area studies currently confront two distinct challenges: rigor and relevance. Last year, Harvard political scientist and Africa specialist Robert Bates characterized area studies as problematic for political science because of their lack of scientific rigor (Bates 1996). He charged that political scientists who work in area studies programs resist "rigorous methods for evaluating arguments" and consequently have "defected from the social sciences into the camp of the humanists" (quoted in Shea 1997). This debate has evolved more recently in the pages of $P S$, where Bates still insists on the scientific-humanistic distinction while calling for a synthesis of rational choice theory and comparative politics - "generalizable knowledge" and "context-specific knowledge," respectively (Bates 1997). In a companion article, Chalmers Johnson rejects such synthesis, arguing that the rational choice "fad" fails to provide "a mechanical alternative to genuine social science analysis" $(1997,173)$. Going beyond the Bates-Johnson debate, Kenneth Prewitt (1996) suggests that area studies risk irrelevance if they fail to confront fundamental challenges from a newly emerging front: a globalizing international environment, where accelerating rates and increasing magnitudes of capital, human, and information flows create new geographies that overlay established notions of "area."

While all academic programs must confront issues of rigor and relevance, two contradictory tendencies in the structure of areas studies programs make establishing and assessing rigor and relevance especially problematic. First, such programs are by definition interdisciplinary, but their curricula rarely include courses that are truly interdisciplinary. Instead, the courses comprising area studies curricula often reflect and reinforce the divisions among fields on the university level. Second, because of the short duration (two years, usually) of student enrollment in master's programs, area studies curricula tend to emphasize specific topics in distinct fields, instead of fundamental and universal research and analytical skills. It is usually assumed that students have developed such skills on the undergraduate level, or will develop them through general course work on the graduate level. Such assumptions prove incorrect in most cases. Students enter graduate school with widely varying knowledge and abilities, and faculty in area studies programs are hesitant to impose rigid skills requirements out of concern with encouraging diversity of training and specialization.

Consequently, area studies programs tend to produce graduates who know much about specific aspects of their "own" region, but who have no larger vision of the fields of inquiry that constitute area studies. Furthermore, introducing students to the empirical "stuff" of a specific region often leads faculty to downplay the importance of helping students develop the "exportable" skills in research and analysis so essential in the social sciences and the nonacademic job market. A limited focus on only a handful of empirical features of a specific region probably shortchanges students even more in the current era of expanding globalizing forces and the consequent transformation of traditional boundaries.

At the Center for Latin American and Caribbean Studies at the University of Connecticut we feel that these challenges do not inevitably undermine the rigor or relevance of area studies, but they do require serious reconsideration of an area studies program's processes and goals. Is the lack of rigorous methodological training a necessary condition of area studies, or merely a tendency? If the latter (as we believe), then the appropriate remedy would be to reconfigure area studies curricula to ensure that graduates are well trained to conduct rigorous research and analysis. Do globalizing dynamics erase the boundaries of traditional areas? No. The fundamental geographic, linguistic, cultural, and even economic characteristics that have defined Latin America, or Africa, or Southeast Asia, or Western Europe continue to define these areas as much now as ever. Do methodology and thematic content in area studies programs need to respond to new technologies and new geographies? Yes.

\section{The Proseminar in Latin American Studies: Redesigning the Curriculum for the 21st Century}

The Center for Latin American and Caribbean Studies at the University of Connecticut has begun redesigning its curriculum to reinvigorate its interdisciplinary mission while simultaneously giving primacy to training students to conduct rigorous research and analysis. In the fall semester of 1996, the Center instituted fundamental changes to its Proseminar in Latin American and Caribbean Studies, the introductory graduate course all students are required to take in their first semester. The course has always been intended to fulfill the Center's interdisciplinary and multicultural mission of uniting fields as diverse as agricultural studies and anthropology, literature and economics, and communications and political science. The specific goals have been to provide new students with both an intensive and broad introduction to the various possibilities for focusing their course work and for developing their research projects. In practice, the pedagogic goals of the original design of the Proseminar had foundered amid the lack of university support for release time or extra funding needed to develop and teach 


\begin{tabular}{|c|c|}
\hline Week 1 & $\begin{array}{l}\text { Unit } 1 \text { - Politics, History, and Anthropology } \\
\text { Ways of Looking: The Politics of Progress, Development, and } \\
\text { Dependence }\end{array}$ \\
\hline Week 2 & Historical Approaches to Dependence and Development \\
\hline Week 3 & $\begin{array}{l}\text { Sociology and History: New Social Movements and the } \\
\text { Rise/Rediscovery of Civil Society }\end{array}$ \\
\hline Week 4 & Library Workshop on Latin American History/Social Sciences \\
\hline Week 5 & Student Presentations of Research Design Critiques \\
\hline Week 6 & $\begin{array}{l}\text { Unit } 2 \text { - Culture and Identity } \\
\text { Art History: Nationalism and Modernism }\end{array}$ \\
\hline Week 7 & Communications and Cultural Studies \\
\hline Week 8 & Literature and Criticism \\
\hline Week 9 & Library Workshop on Latin American Culture and Identity \\
\hline Week 10 & Student Presentations of Research Design Critiques \\
\hline Week 11 & $\begin{array}{c}\text { Unit } 3 \text { - Development Studies } \\
\text { Development, Underdevelopment, Wealth, Distribution, and Growth }\end{array}$ \\
\hline Week 12 & Agriculture and Economic Development \\
\hline Week 13 & The International and National: Structural Adjustment \\
\hline Week 14 & Library Workshop on Global and Regional Development \\
\hline Week 15 & Student Presentations of Research Design Critiques \\
\hline
\end{tabular}

a dynamic and truly interdisciplinary course. Consequently, the course had evolved into a "topics" course that focused on the field of the individual teaching it, reinforcing divisions among fields while neglecting cultivation of rigorous analysis as an explicit goal.

In the fall of 1995, the Center began designing a new model for the Proseminar that would fulfill the original objectives while drawing on the specific strengths of the Latin American studies faculty across the university. The essential elements to be included were: broad and interdisciplinary faculty participation; a workshop model emphasizing development of fundamental skills; and extensive training in the use of research resources available through the library. The overall success of the course has led to consideration of requiring it of all master's students in the Division of International Affairs. Still, some aspects require revisions to both design and procedure.

\section{An Interdisciplinary Workshop}

The Proseminar's new design combines the various disciplines into three core units: (1) Foundations: history, political science, anthropol- ogy; (2) Identity: art, literature, communications; and (3) Development Studies: agricultural and resource studies, economics, and public administration. This specific configuration of the course reflects the core fields in area studies at the University of Connecticut, but may be adapted to the thematic and programmatic goals of other centers. The structure requires a "course coordinator" (instructor of record) and three "unit coordinators" in charge of coordinating the design and teaching of each five-week unit in conjunction with relevant faculty. In the fall of 1996 the instructor of record also coordinated the first unit. Additionally, the course requires a Latin American bibliographer on staff in the main library to conduct three workshops on library research and accessing online sources.

The course is designed as a workshop that requires significant involvement from the students. It requires summer reading prior to actually joining the program, three short critical reviews of the literature on a particular topic, and three oral presentations based on the written assignments. Additionally, each student must produce an extended bibliography, using a full and standard- ized style, on a particular topic which could be developed into a master's thesis.

This new structure is intended to meet three sets of goals: (1) introducing students to the basic concepts and theories of a particular field (e.g., economics) in each of the core units, including the current state of the art of theoretical debates; (2) introducing students to research approaches and the formulation of research questions in each of the three core units; and (3) helping students develop essential analytical and presentational skills. These goals inform the basic structure of each of the three units, and are achieved through a combination of reading, discussion, hands-on exercises, and short papers. Providing comprehensive knowledge of a particular field is impossible within the confines of a semester-length course; nor can all formal fields of study be covered. The strength of the Proseminar rests with its emphasis on bringing students rapidly and broadly into a multidisciplinary field and equipping them with the theoretical tools and research skills necessary for producing an original research project.

\section{The Five-Week Model}

Each unit consists of five meetings (see Table 1), with the first three class sessions structured like most graduate seminars. The fourth week is devoted to a library workshop, and the fifth is reserved for student presentations. During the first three weeks of each unit, students read a set of required articles and/or a book, and discuss critically their perspectives, approaches, methodologies, and conclusions in class. Since this is one of the first graduate classes the students will have taken, it was determined that students would be required to participate only in gradually increasing degrees over the course of each unit. So, in the first class of a given unit the instructor leads the discussion, even to the extent of providing a short lecture and outline of issues and debates. In the second meeting, the students are expected to contribute more, as they apply their understanding from the previous session. Finally, 
in the third meeting, the students should structure the class discussion.

During the fourth week of each unit (weeks 4, 9, and 14) students attend a workshop with the Latin American bibliographer, who teaches research strategies, introduces the various media (including the latest electronic resources) for conducting scholarly research, and advises on data/information collection for the short papers. No readings are assigned during the fourth week of each unit, giving students more time to research a topic and prepare their presentations and papers.

Each library workshop is oriented toward accessing sources in the academic fields pertaining to the specific unit. The first meeting, by necessity, also serves as a general introduction to library facilities and policies and provides basic instruction on developing search strategies using boolean operators, formulating and reformulating search statements, and effectively using the Library of Congress subject vocabulary. While some of the instruction may seem fundamental, particularly in the first session, these are techniques and technologies that may not have been explicitly introduced to students elsewhere. Given the accelerating pace of change in library research methods, due in large part to the explosion of new electronic resources, formally integrating library

bibliographic instruction into the Proseminar is crucial.

The fifth and last week of each unit (weeks 5,10 , and 15) is dedicated to presentations of student research, which are strictly limited to fifteen minutes for presentation, with two minutes for questions or comments from the class. This training is important for enhancing student performance in other classes over the two year course of study, and for developing a professional style in oral presentation. Confusing and disjointed oral presentations are common in all realms of activity, and have been of special concern within the Latin American Studies program at UConn.

Explicitly focusing the attention of the entire class on presentational style and critical thinking helps students identify and develop these essential skills.

In addition to giving a presenta- tion and writing a paper at the end of each of the three units, students must produce a bibliography of some thirty sources that might be used for a thesis project. This annotated bibliography is evaluated by the Latin American bibliographer at the end of the semester. This exercise serves several purposes. First, it communicates to students that they are in the program to produce a research project and forces them to begin considering a topic from the very first semester. Students will quite possibly change their research topics; but even in these cases the exercise will provide valuable experience. Second, it calls special attention to bibliographic style, one of the main areas of evaluation. Third, it forces students to search for a greater variety of sources than is required in the three short critical reviews. Finally, the bibliography provides the Latin American bibliographer with information on students' interests and abilities for subsequent advising over the course of their studies.

\section{Grading Student Performance}

The structure of the course makes it labor intensive. The course coordinator and unit coordinators must make sure that all participants are informed and reminded of the class schedule, and briefed on what to expect from the students. For student presentations, a summary evaluation sheet was created and reproduced to help ensure consistency of evaluation. Additionally, the course coordinator attended all presentations and shared responsibility for evaluating the presentations. These helped create a sense of continuity for the students.

Still, the strong faculty consensus on the quality of the individual presentations showed that consistency of evaluation across units was not at risk. With only a few exceptions, the grades showed notable consistency, requiring only minor discussion. Similarly, evaluations of the short papers accompanying the oral presentations (a task born exclusively by the relevant unit coordinator) showed considerable consistency. This consistency was achieved through considerable effort and close scrutiny of the papers. Unit coordinators, conscious of the introductory nature of the course and operating with only limited familiarity with the students, wrote extensive comments and gave careful consideration to their evaluations.

\section{Assessment and Modifications}

Although student evaluations at the end of the semester revealed broad satisfaction with the course, they confirmed our own identification of areas requiring attention (see Table 2). Students were noticeably less positive in five areas (in order from least satisfaction): (1) organization, (2) fulfilled objectives, (3) clear assignments, (4) clear objectives, and (5) presentation of the material. These areas received an average of 6.02 on a scale of 10 , compared to 7.56 for areas like stimulating interest, accessibility of instructors, and preparation of instructors. An average rating of 6 on a 10 point scale is not bad. Also, it should be noted that this pattern (i.e., lower scores on organizational dimensions) reflects the performance of all classes across the university, except that the Proseminar's evaluations are somewhat lower.

The results of course evaluations could be artifacts of comparing a graduate seminar to all classes offered at the university, including undergraduate lecture courses, which are by nature more structured. Also, there appeared to be two extremely low outliers in a survey of only ten students. Still, we feel the student evaluations reflect, at least in part, the challenges posed by the course's complex structure. We have identified several specific areas in the course design that require revisions, or at least reconsideration: (1) communication of objectives to students, (2) integration of the library component into the course, (3) facilitating critical discussion of assigned reading, and (4) broader class involvement in discussing student presentations.

\section{Communication of Objectives}

Communication of objectives is a crucial area of concern for any 
TABLE 2

Frequency Distribution of Student Evaluations of the Proseminar

\begin{tabular}{|c|c|c|c|c|c|c|c|c|c|c|c|}
\hline & \multicolumn{5}{|c|}{ Unacceptable } & \multicolumn{6}{|c|}{ Outstanding } \\
\hline Organization & & 2 & & 1 & 1 & 1 & 1 & 1 & 1 & 1 & 9 \\
\hline Clear objectives & & 2 & & 1 & & 1 & 2 & 2 & 2 & & 10 \\
\hline Stimulated interest & 1 & 1 & & & & 1 & & 3 & 2 & 1 & 9 \\
\hline Graded fairly & & 1 & & 1 & 1 & & 1 & 1 & 5 & & 10 \\
\hline Appropriate exam & & 1 & & 1 & 1 & 1 & & 1 & 2 & & 7 \\
\hline Accessibility & & 1 & & & & 1 & 2 & & 2 & 4 & 10 \\
\hline Interest, concern & 1 & & & & & 1 & 1 & 1 & 3 & 3 & 10 \\
\hline Preparation & & 1 & & & & 1 & 1 & 2 & 1 & 4 & 10 \\
\hline
\end{tabular}

course, but especially for a course that is the cornerstone of our program. The Proseminar should embody and communicate to the students the philosophy and orientation of the entire program. Furthermore, the complex structure of the course and its emphasis on skills requires a constant effort to communicate the purpose of every aspect to students. However, the novelty of this course to the instructors and the coordination and communication barriers mentioned above inhibit this constant reiteration of objectives.

One way to facilitate the communication of objectives by instructors is to itemize the reasons for the course and for each exercise, and asking all instructors to communicate these to the students. Such itemization must be made with the consultation of all instructors to ensure consensus on the course's mission. A mission statement that is simply handed down to participating faculty would be likely to be poorly communicated to the students, if at all.

\section{Integration of the Library Component}

Two aspects of the library component to the course need attention: the placement of the workshops in the weekly schedule and the extended bibliography. Some of the students expressed a preference for scheduling the first library workshop earlier in the semester; week 3 instead of week 4 , possibly. They were concerned that the foundational nature of the first workshop meant that there was little time to absorb all the information and develop a research topic for presentation by week 5 . It had seemed natural to the Curriculum Development Committee that the week off from assigned reading should occur just before presentations, and that all units should have exactly the same order of events so as to minimize confusion. Additionally, it was felt that students needed maximum exposure to the subject matter in each unit before they were required to conduct research. It seems worth reconsidering this logic, and switching the third and fourth weeks of each unit; that is, scheduling the library workshop one week earlier in each unit, followed by one week for discussion of assigned reading.

The extended bibliography was devalued by the students partly because it is graded on a pass-fail basis. It is an easy remedy to emphasize the importance of this requirement of the course by assigning part (e.g., 10\%) of the final grade to successful completion of this important assignment.

\section{Critical Discussion of Assigned Reading}

Although the course is oriented toward oral and written presenta- tions of student research, an equally important component is the nine weeks of regular seminar, during which assigned readings are discussed. Cultivation of high quality discussion was restricted slightly by the need to use nine different faculty members (three in each unit) instead of only three (one faculty member responsible for each unit). Because the university could not provide the release time or extra compensation to faculty participating in the course, the Center depended on the ability of faculty to volunteer their time. Having nine different instructors lead the nine weeks of regular seminar produced some disorientation and timidness among the students. Also, the relative lack of surveillance resulting from this structure led students to deemphasize further the assigned reading in favor of the tasks for which they would be most directly evaluated.

To some degree, students tend to focus on the specific written and oral assignments in all graduate seminars, but the disorientation and timidness engendered by being exposed to so many different instructors is specific to the Proseminar's interdisciplinary structure. One possible remedy is to reduce the number of instructors to three, one for each unit. This is attractive because it minimizes complexity, but at the cost of broad faculty participation and student exposure to different views and approaches. This issue was one that 
was identified early in our curriculum development meetings, and was resolved more by resource constraints than by active identification of a preferred structure.

A second remedy involves providing students with specific discussion questions for each week's reading. This also is promising in terms of both costs and benefits. It should be relatively easy to compose a set of discussion questions for readings that presumably speak to the instructor who assigned them. At the same time, specific questions should help both students and faculty focus on central issues.

\section{Broader Class Involvement in Discussing Presentations}

Students demonstrated some thoughtful insights during their classmates' presentations, but the burden of raising discussion questions was borne by the instructor(s). Most likely, two factors limited broader class participation. First, students likely were distracted by thoughts of their own presentations and papers. Because of time constraints during the semester, students must submit their papers during the presentation seminar. In most graduate courses, we allow students to submit the papers accompanying their presentations the following week in order to include insights from the class discussion. Requiring both the papers and presentations on the same day probably limited students' attention to their peers' work. Second, the sheer variety of material covered in this first-semester class overwhelmed some students.

Also, time constraints during the presentation seminar at times cut short class discussion. The presentations on identity issues, for instance, generated lively class discussion. However, with ten students presenting during a single seminar meeting, class discussion pushed the meeting time to over three and a half hours, and even then discussion was forcibly cut short. This raises a more fundamental question of whether this class time should be focused on the individual presentations, or expanded to include broad class discussion. One way to encourage wider participation is to have two meetings for presentations, assuming a minimum of eight to ten seminar participants. Still, the single meeting for presentations forces a discipline on the class that is fundamental to effective communication inside and outside academia.

\section{Conclusion}

Area studies programs need to be concerned with training students in rigorous analysis, as do all academic programs. Additionally, the blurring of the boundaries of traditional geographic and cultural areas as a result of powerful political, economic, and technological forces operating on a transnational level pose new challenges to area studies programs to develop approaches that cross the boundaries of traditional fields. Furthermore, emerging research technologies and job market requirements accentuate the need to reemphasize fundamentals skills in research and analysis in order to prepare students for a variety of professional and academic careers. These heightened concerns reflect realities that are at least partly addressed by our interdisciplinary research and skills workshop, required of all first-semester students. Overall, we believe in the continuing viability and necessity of area studies programs. In that spirit, we embrace the need for curriculum innovations that contribute to the continuing success of our students well after they graduate. Though seemingly paradoxical, the best response to the challenges and contradictions confronting area studies, we feel, is to return to the essentials of research, analysis, and oral and written communication.

The syllabus and supporting documents for the Proseminar are available upon request. Please send requests to:

Outreach Office

Center for Latin American and

Caribbean Studies

843 Bolton Rd., U-161

University of Connecticut

Storrs, CT 06269

\section{References}

Bates, Robert H. 1997. "Area Studies and the Discipline: A Useful Controversy?" PS: Political Science and Politics 30(2): $166-$ 69.

Bates, Robert H. 1996. "Letter from the President: Area Studies and the Discipline." APSA-CP: Newsletter of the APSA Organized Section on Comparative Politics 7(1): 1-2.

Johnson, Chalmers. 1997. "Preconception vs. Observation, or the Contributions of Rational Choice Theory and Area Studies to Contemporary Political Science." PS: Political Science and Politics 30(2): 170-74.

Prewitt, Kenneth. 1996. "SSRC, ACLS and the Reexamination of Area Studies." LASA Forum 27(1): 10-12.

Shea, Christopher. 1997. "Political Scientists Clash Over Value of Area Studies." The Chronicle of Higher Education, January 10, A12-A13.

\footnotetext{
About the Author

John T. Morris was assistant professor in residence at the University of Connecticut and Brown University from 1994 to 1997 through the Latin American Studies Consortium of New England, a Title VI National Resource Center that includes the University of Massachusetts, Amherst, and more recently Yale University. In 1998 he accepted a position in international marketing communications and product management for a major computer software company.
} 